\title{
Democratizing Innovation. A Geo-Entrepreneurial Analysis and Approach through the Company Democracy Model
}

\author{
Evangelos Markopoulos ${ }^{1,2}$, George Markopoulos ${ }^{3}$ and Hannu Vanharanta ${ }^{4,5}$ \\ ${ }^{1}$ University College London, School of Management, Gower St, Bloomsbury, WC1E 6BT, \\ London, United Kingdom \\ ${ }^{2}$ Turku University of Applied Sciences. Faculty of Engineering and Business \\ Joukahaisenkatu 3, ICT-City, C-wing, FI-20520 Turku, Finland \\ ${ }^{3}$ Westminster Kingsway College, 211 Grays Inn Rd, WC1X 8RA, \\ London, United Kingdom \\ ${ }^{4}$ University of Vaasa, School of Technology and Innovations, \\ Wolffintie 34, 65200 Vaasa, Finland \\ ${ }^{5}$ Poznań University of Technology, Plac Marii Skłodowskiej-Curie 5, \\ 60-965 Poznań, Poland \\ e.markopoulos@ucl.ac.uk,geomark1919@gmail.com,hannu@vanharanta.fi
}

\begin{abstract}
Even that thinking, and innovative thinking, in particular, is supposed to be borderless and unbiased, it seems that most of the innovations globally derive from regions that have built a brand name on it. This limits the opportunities to bright ideas form bright people outside the innovation hubs, resulting in a general loss of intellectual capital for the global economy. This paper aims to democratize innovation by redefining geo-entrepreneurship through a reverse innovation framework that exposes the hidden intellectual capital around the world, evaluates innovation drives and opportunities and empowers the development, commercialization and utilization of innovation. Based on the Company Democracy Model the proposed framework impacts reversely national brain-drain contributes to innovation scouting, strategic partnerships, and redistributes success opportunities. This geo-entrepreneurial approach identifies innovation potential globally, reduces inequalities among all those who can and want to create opportunities regardless of where innovation takes place and by whom.
\end{abstract}

Keywords: Geopolitics · Geo-economics · Geo-entrepreneurship · Democracy · Reverse Innovation · Brain drain · Technology · Innovation · Management $\cdot$ Strategy $\cdot$ Investments $\cdot$ Startup

\section{Introduction}

In the last two decades, the term 'innovation' drives the global economy and development. The rapid and impressive advancements of technology in hardware, software, and communication above all, eliminated distances, created new markets and generated countless types of clients and needs. The continuous quest for the faster, cheaper, better but also smarter products or services created a global entrepreneurial revolution led 
primarily by students or young professionals and followed massively by the millennials later. Innovation created an entrepreneurial DNA-code with common characteristics and traits on all modern innovators [1].

According to Thomas Friedman and his globalization theory 3.0 [2], the world is indeed flat, and the evolution of innovation makes it not only flat but small as well. However, the way innovators innovate, the cost of innovation, the innovation effectiveness, the areas of innovation, its impact to the society, to the local and the global economies, to the national competitiveness advantage, to the generation of human intellectual capital and to many other dimensions seems to be very different around the world.

Access to technological resources, funding opportunities, market maturity, buying power, exposure and visibility, and partnerships is not equally distributed locally, nationality and internationally.

Such inequalities can be identified in various parts of the world where thinkers from followers are differentiated by political, economic, social, and technical (PEST) factors and incentives. Lack of data, information, knowledge, as well as opportunities and advantages based on political culture, create either brain drain from those who leave, or brain gain from those retained or imported when incentives are given. Such intellectual capital swifts, impact significantly the development and the progress of national economies and markets. Losing brilliant minds, due to lack of opportunities to be developed and rewarded, is the same as importing brilliant minds to recover the inactive ones in a country due to insufficient local or national innovation strategies and culture.

\section{Innovation Brands}

The value and impact of an innovative idea or even a start-up are usually influenced by the country or city the innovations derive. In the US, $\$ 135,4$ billion spend by Venture Capitals and other financial sources the period of 2011-2014 with $60+\%$ in California. Specifically, from the $\$ 47.3$ billion invested in 2014, 35.6 billion ended up in only three states (New York (4.5), California (27.0), and Massachusetts (4.1)) [3]. Furthermore, 22 of the 27 billion spends in California went to the San Francisco (Bay) area. The same implies to the types of innovations being developed. In 2014 in the US, 41\% of the innovations are in technology, $13 \%$ in healthcare, and $8 \%$ in the renewables (energy). In a similar way the 2 nd quarter of 2019 , UK gathered $€ 3$.2billion in tech investments, France 1.8 and Sweden 1.4.

These figures indicate that innovation funding is not spread equally across cities, states or countries but unequally to the ones that have developed an innovation brand name regardless of their population size. This also indicates that the areas or innovation are very limited to what is the trend and not actually what is truly useful. This created a biased approach to what is innovative and what is not and to what shall be funded and what shall not. Terms like Medtech, Cleantech, and especially Fintech monopolized the interest, but life can be much more meaningful without having advanced banks.

A possible explanation of this phenomenon could be that the innovation branded locations attract more investors who wish to invest locally and to trendy innovations. Another explanation could be that investors can be biased towards funding Silicon Valley-based startups than others located in innovation deserts, areas that seem to have a distance from the innovation trends that dominate the public opinion. This thinking, and 
reality to an extent make innovation funding easier for those being at the innovation branded locations and very difficult of those outsides of it. However, limiting investors to invests in what is withing their region and not consider much what is around or outside of it can be a highly risky logic. Another risk is the return on investment which can be less from the investments done in innovation branded locations but more if done outside of them due to the reverse innovation theory [4]. Investing in less privileged locations reduces the cost of innovation development and increases the return on investments once those innovations are brought to the mainstream markets. To tackle this challenge investors, either private or public, shall approach innovative ideas unbiased from the city, the country or the sector they come from.

It is a need for the development of geo-entrepreneurial thinking by understanding the world and what each place has to offer to an investment at a specified subject, under specific conditions for a specific time. As all people are equal and therefore they can all think, it is for certain that using geo-entrepreneurial thinking the opportunities for both the investors and the innovators can be multiple with greater benefits. The same of course can be applied not only to people but to states of countries that under current or expected political or operational conditions can be ideal for either innovation development or ideal target groups for innovation adaptation.

\section{Geo-Entrepreneurship by Example}

The term geo-entrepreneurship describes and analyzes the techno-economic entrepreneurial geography. It is the process of identifying the best areas innovation investments can be made at a specific instance, time, subject and target group (market).

An example of geo-entrepreneurship can be given on the innovation area of Cultural Digital Heritage which is a growing market with tremendous opportunities for innovative technologies on the digitization preservations, dissemination and commercialization of natural heritage monuments, and other elements [5]. The European Union invested in this sector 1.46 billion euros from the 78 billion of the Horizon2020 Research and Innovation program budget [6].

In this case and under the geo-entrepreneurship theory, the best possible innovators in this field could be considered the ones deriving primarily from Egypt. The county fulfills many of the geo-entrepreneurship conditions such as original and valid knowledge to be developed, quality of software development, incentives to entrepreneurs, and a wide market for the technology adaptation.

Specifically, since 2000, Egypt invested part of its national development strategy on the digitization and commercialization of its cultural heritage. CULTNAT, the National Center for Cultural and Natural Documentation received world-class international awards, distinctions and recognition for its research on this field and its support to active contributors [7]. Part of the same national strategy has been the development of the Software Engineering Competence Center (SECC) and the Technology Innovation and Entrepreneurship Center (TIEC), among other governmental organizations for the development of the Egyptian innovation. SECC trains, supports and certifies professional software engineers in start-ups, SMEs, but also large organizations, with high impacts software engineering standards and practices such as the CMMi, which is really followed in many developed countries due to their tedious development process on 
software quality [8]. TIEC has been developed to drive innovation and entrepreneurship for the benefit of the national economy acting as a catalyst for the academia-industrygovernment triptych [9]. Today TIEC is a leading innovation hub in the region and provides funding schemes, accelerator programs, competitions, and other activities to support the Egyptian start-ups and not only. Besides the maturity of the country on the cultural heritage digitization, digital museums and digital libraries, the quality of software engineering, and then start-ups entrepreneurial support, it must be noted that Egypt has since 1990 a ministry dedicated to the development of ICT. The Egyptian Ministry of Communication and Information Technology is the driving force for the Egyptian technological revolution. Furthermore, the country has endless resources from the 43 universities (20 public with 2 million students and 23 private with 60.000 students) that operate, in which engineering is the dominant course/program of studies.

Taking the geopolitical analysis furthermore, Egypt speaks Arabic, besides English and French. Arabic is a language of 22 countries nearby with a total population of 450 million. Egypt has always been a leading Arabic nation, hosting the Arab League headquarters in Cairo since its establishment, and is one of the most, if not the most, influential country in terms of engineering and technology in the Arab world with highly recognized engineers. These facts, along with the continuous growth of the Egyptian GDP [10] and its 14 technological parks, indicate the wide target group Egyptian innovations can have in adaptation and commercialization.

The given example can be graphically presented in figure 1 with the geo-entrepreneurial elements satisfied in this case as an advantage compared to other countries on the areas of Digital Cultural Heritage, and not only.

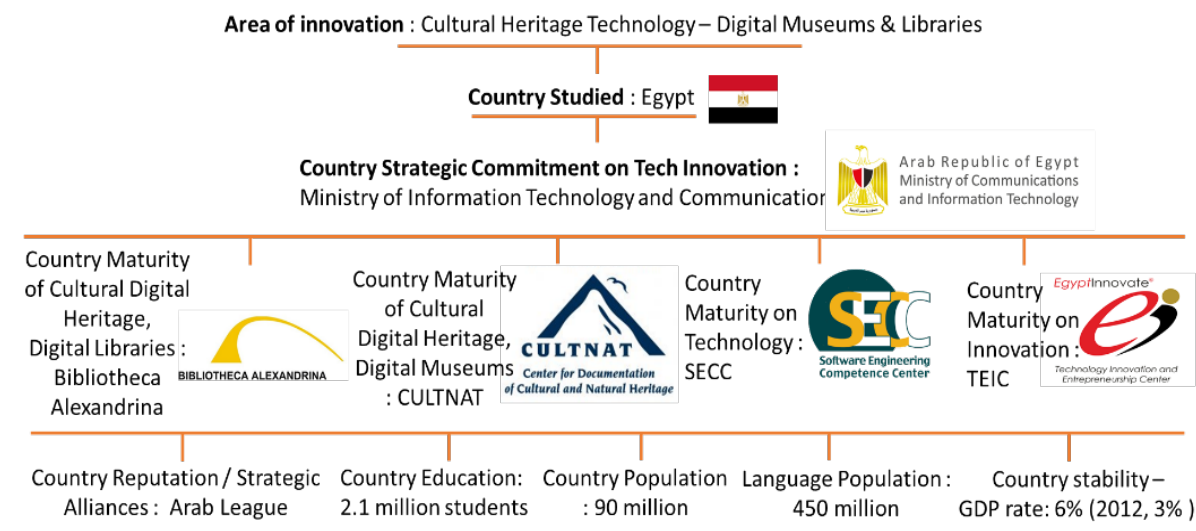

Fig. 1. Example of geo-entrepreneurial elements

Similarly, to Egypt, there could be cases like Botswana whose technological growth and commitment to software engineering grow significantly after the adaptation of the ITIL by the government. Zambia is also an innovation development hub considered as the country with the best female entrepreneurship results. It is also worth paying attention to small size countries like Malta and Cyprus who were ranked at the 27th and 28th place respectively by the World Intellectual Property Organization in 2019 [11]. 


\section{Geo-entrepreneurship elements}

There is a significant difference between geo-entrepreneurship and international business development, even though both involve foreign investments. As of today, the development of established organizations in foreign markets has been driven from economies of scale or cost reductions motives.

Large organizations invest in foreign countries the development of their operations, production, distribution, supply chain, and innovation after analyzing the related costs and target markets. Such initiatives can not be considered as an entrepreneurial strategy since there is no entrepreneurial risk in them. The expansion is well calculated, the costs are proven lower compared to the ones in the organization's country, and the access to the markets is practically justified.

On the other hand, the geo-entrepreneurs are primary start-ups or organizational spin-offs aiming to explore the opportunities a different country offers to develop innovation and operate either in the sphere of influence of that country or globally. Geoentrepreneurs seek the innovation expertise on a specific sector, subject or service to be delivered best at, and from, a specific country once certain pre and post conditions are fulfilled.

Today international business development and foreign investments are made through several country ranking criteria. The McKinsey Global Institute identifies Azerbaijan, Belarus, Cambodia, Ethiopia, India, Kazakhstan, Laos, Myanmar, Turkmenistan, Uzbekistan, and Vietnam as the less heralded and more geographically diverse outperformers [12]. MSCI (Morgan Stanley Capital International) index on the other hand on its 27 emerging economies includes among others Peru, Colombia, Poland, Czech Republic, Pakistan, Thailand, and even Greece despite its devastating financial crisis and continuous austerity programs of the last decade which still go on. [13]

On the other hand, no such indexes, rankings or investment elements exit today to guide Geo-entrepreneurs on ideas and innovation evaluations from specific countries. The main reason for this gap is the fact the geo-entrepreneurship is innovation-driven, with a great degree of fuzziness, and not conventional product or service driven that have a great degree of certainty due to their existing expertise on the development and distribution process. Tables 1 indicates the main Geo-Entrepreneurship criteria.

Table 1. Main geo-entrepreneurial elements for investors

\begin{tabular}{|c|c|c|c|}
\hline \multicolumn{4}{|c|}{ Geo-entrepreneurial elements } \\
\hline Talent Pool & Country size & $\begin{array}{l}\text { Country technolog- } \\
\text { ical growth }\end{array}$ & Corruption \\
\hline Intellectual capital & $\begin{array}{l}\text { Governmental support on } \\
\text { the field }\end{array}$ & $\begin{array}{l}\text { County investment } \\
\text { programs }\end{array}$ & Bureaucracy \\
\hline Human recourses & $\begin{array}{l}\text { Governmental entrepre- } \\
\text { neurial support }\end{array}$ & $\begin{array}{l}\text { Common Borders / } \\
\text { Unions / Leagues }\end{array}$ & Target Market \\
\hline $\begin{array}{l}\text { University gradu- } \\
\text { ates }\end{array}$ & $\begin{array}{l}\text { Country field expertise } \\
\text { (innovation area) }\end{array}$ & Common Cultures & $\begin{array}{l}\text { Growing } \\
\text { ents }\end{array}$ \\
\hline Number of patents & Country growth & Common Language & Legislation \\
\hline
\end{tabular}




\section{$5 \quad$ Reverse Innovation}

Today, working in emerging countries is a strategy and privilege of large-scale organizations by moving their production and operations primarily for cost efficiency. However, such strategies restrict benefits that can be obtained from investing in the intellectual capital the emerging countries have towards achieving reverse innovation. Geoentrepreneurship challenges this by replacing cost reductions with the utilization of the intellectual capital offered in emerging countries to achieve reverse innovation in two dimensions.

In the first dimension, innovation investors aim to identify ideas, prototype designs, working prototypes and actual innovative products and services with high potential, performance or sales developed while developed with minimal cost. Such innovations can be brought back to the high-end innovation markets, under new branding and marketing strategies applied in the developed countries that can increase the profit margins by selling high and keeping the implementation costs low in the emerging country.

In the second dimension, the investment can be direct to the emerging country without necessarily bringing the innovation to the developed country but benefit directly from the massive target groups the innovations are applied. In this case, reverse innovation can be obtained in a reverse way by bringing technology, expertise and ideas from the developed country to enhance the existing technology by using the human recourses of the emerged country, to strengthen its functionality and operations on the markets the innovation exists without indicating or applying change of ownership (Fig. 2)

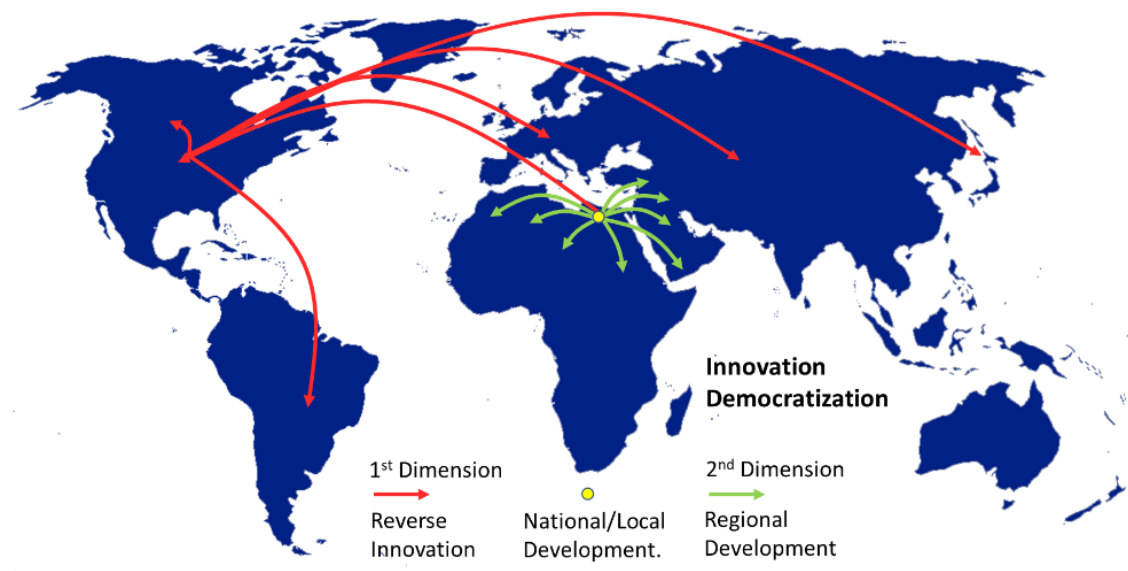


Fig. 2. The Geo-Entrepreneurial Double Reverse Innovation.

\section{Democratizing innovation}

Geo-entrepreneurship can be achieved with geostrategic thinking, the unbiased thinking needed to clearly and fairly identify opportunities behind people's colors, sex, religions, nationalities, education, lifestyle, social and economic background. Knowledge does not discriminate, and innovative thinking can be achieved by anyone and anywhere who wants to think practically, rationally and effectively. Geo-entrepreneurship can also be defined by innovation democratization.

It is the democratic mentality, thinking and acting that offers the opportunities, circumstances, and infrastructure to those that indicate innovativeness.

Therefore, Innovation opportunities, funding, and support cannot and shall not be a privilege for the ones within the innovation branded locations. It is not only San Francisco, New York, Boston, London, Berlin, Singapore, Beijing or Tokyo that grow the best ideas, in fact, due to the competition and the plethora of ideas the best might get lost in the crowd or never get the chance to be presented. The democratization of innovation via geo-entrepreneurship can reveal the same impressive, or even more impressive ideas and innovations from places not considered as innovation hubs.

The effective adaptation of the democratic geo-entrepreneurship from large scale organizations, investors and even governments can empower the global economy by motivating more startups around the world to keep on innovating knowing that they have a fair opportunity wherever they are.

\section{The Democratic Geo-Entrepreneurship Model (DeGeoEM)}

The Innovation Democratization for Geo-Entrepreneurship can be implemented through the Democratic Geo-Entrepreneurship Model (DeGeoEM), a derivative of the Company Democracy Model (CDM).

The Company Democracy Model is a knowledge management process framework that transforms organizational knowledge into innovation, competitiveness, and extroversion [14]. The model is composed of six levels evolving from level 1 when knowledge is democratically elicited from anyone in any organization, all the way to level 6 where the knowledge, and those who contributed, are transformed into organizational assets. Variations of the Company Democracy Model has been used to design fumeworts for New Product Development [15], Corporate Entrepreneurship [16], Governmental (Public Sector) Entrepreneurship [17], Green Ocean Strategy [18], Agile Startup Business Planning [19], Teaming [20], and other areas of management.

The Democratic Geo-Entrepreneurship Model (DeGeoEM) maintains the six levels of the Company Democracy Model approached from four different dimensions (Fig. 2) where each one can be considered as a different management methodology that can be implemented separately or jointly with the rest to achieve Geo-Entrepreneurship. 


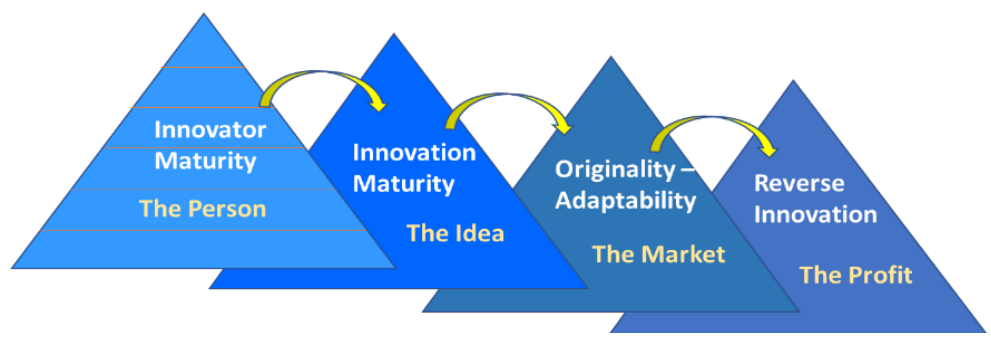

Fig. 2. The Democratic Geo-Entrepreneurship Model (DeGeoEM) Dimensions

The first dimension indicates the maturity degree of the country the innovation exists or the startup operates. The second dimension indicates the degree of reverse innovation that can be achieved, meaning the success an innovation brings to the investor when it goes to a developed country. The third dimension indicates the credibility of the innovator or the startup that has or runs the innovation. The fourth dimension indicates the innovation strength in originality, adaptability and intellectual property.

\section{DeGeoEM Dimension Levels}

Each one of the four DeGeoEM dimensions is composed of six levels in an evolutionary path indicating the completion of one level after the other (Fig. 3).
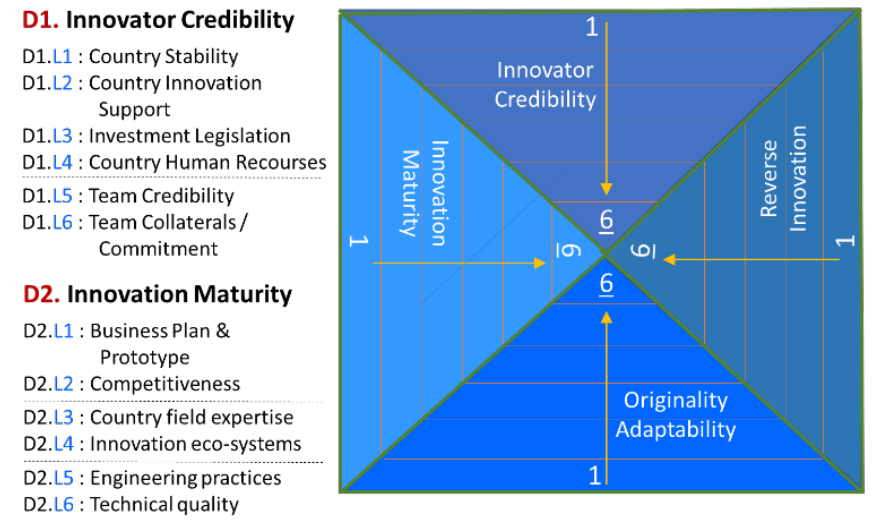

D3. Originality Adaptability D3.L1 : Publications D3.L2 : Patents

D3.L3 : Standardization D3.L4 : Maintainability D3.L5 : Language adaptation D3.L6 : Culture adaptation

D4. Reverse Innovation

D4.L1 : International Standards D4.L2 : International needs

D4.L3 : International ecosystems/connectivity

D4.L4 : Unit cost reduction D4.L5 : Production Speed D4.L6 : Users/Clients Growth rate

Fig. 3. Democratic Geo-Entrepreneurship Model (DeGeoEM) Dimension Levels

The levels of the first $\left(1^{\text {st }}\right)$ dimension (Innovator Credibility) are grouped into two categories. The first four levels analyze the credibility of the innovators' space. Specifically, level 1 deals with the identification of the country stability. Level 2 evaluates the country's innovation support, level 3 analyses the investment legislation and level 4 evaluates the country's human recourses that can be used by the innovator. The last two levels form the second category deals with the innovators' team structure and 
commitment. Level 5 evaluates the innovators' team structure and coherence, while level 6 verifies the team collaterals and commitment to their innovation.

The levels of the second $\left(2^{\text {nd }}\right)$ dimension are grouped into three categories. The first category consists of innovation readiness with level 1 to identify the completeness of the business plan and the operations of a working prototype, while level 2 identifies the innovation competitive elements. The second category deals with the innovation infrastructure maturity. Level 3 evaluates the country's expertise in the area of the application and level 4 identifies the existing innovation eco-systems need to empower the development and adaptation of the innovation. The last category deals with technical maturity. Level 5 analyzes the software engineering practices used in the development of the innovation, or other reliable engineering practices, if not technology, and level 6 evaluates the technical quality of the innovation implementation.

The levels of the third $\left(3^{\text {rd }}\right)$ dimension are also grouped into three categories. The first category deals with the originality of the innovation. This is archived at level 1 with publications, awards and competitions that verify the originality. Level 2 deals with the patents, copyrights and intellectual property right actions applied to the innovation. The second category is related to technical agility. Level 3 evaluates the standardization used on the development of the innovation and level 4 evaluates the degree of maintainability. The third category deals with cultural adaptation elements. Level 5 analyzes the language adaptability and level 6 analyzes the cultural adaptability.

The levels of the fourth $\left(4^{\text {th }}\right)$ dimension are grouped into two categories. The first category deals with internationalization compliance. Level 1 analyses the international standards the innovation follows in order to be easily adopted in developed countries. Level 2 analysis the relationship of innovation solutions with similar needs in the developed countries. Level 3 analyzes the degree of compatibility with the international ecosystem in terms of functional and technical connectivity (IoT, etc). The second category is related to the actual reverse innovation drives. Level 4 analyzes the unit cost reduction, level 5 deals with the production speed achieved and level 6 deals with the users/Clients Growth rate.

It must be noted that not all innovations need to reach level six in all dimensions as this is not necessary or feasible based on the stage the innovation is assessed.

\section{Geo-Entrepreneurship controlled evolution.}

The four dimensions of the DeGeoEM can be executed either in parallel or in any order suites the investor's strategy. However, the following order of Innovation Credibility, Adaptability and Originality, Innovation Maturity, and Reverse Innovation is a path recommended as the investments are primarily on foreign countries where the credibility of the innovators and the country is the primary concern.

In general Democratization and Democracy can be quite beneficial but risky as well. Providing opportunities to all does not mean that all can utilize the opportunity. Therefore the risk factors on innovation investments in foreign markets and especially in the emerging countries, where many development parameters could be unstable, is quite high but on the same time the degree of profitability once an investment is executed successfully is inversely related to the risk especially when reverse innovation is achieved. (Fig. 4). 
The evolution of the maturity and effectiveness of innovation, but also the reduction of risk can be divided into three stages achieved with the completion of two DeGeoEM levels in each. The first ( $\left.1^{\text {st }}\right)$ stage is the achievement of success at the domestic or local level. It is the first milestone on which the innovation proves its operations and that the innovators and the startup can stay together after success. Research indicates that $75 \%$ of the startups fail after the first success of receiving funding [21]. Thus the risk of achieving the first two levels is quite high. The second (2nd) stage is where the innovation succeeds at international or even at the regional level. This stage proves the internationality of the innovation, its strength on being accepted, able to penetrate and compete in other markets, in other cultures and against local competitors. Lastly, the third $\left(3^{\text {rd }}\right)$ stage is where reverse innovation is achieved, indicating readiness and maturity to move to developed nations and compete successfully and profitable in markets with high buying power and consumerism.

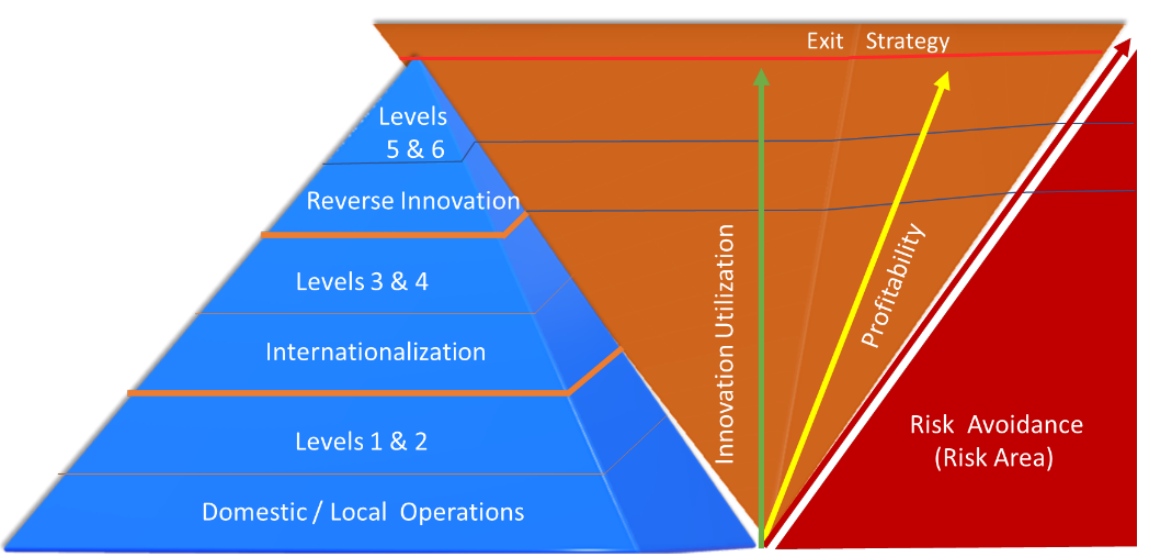

Fig. 4. Innovation maturity, profitability, and risk relationship

\section{The Democratic Geo-Entrepreneurship Model Value}

The Democratic Geo-Entrepreneurship Model is supported by a scorecard that determines the degree of investment security and startup operations success. The scorecard is based on the values scored on each dimension per case. The values are based on the completion of each level in each dimension.

The maximum net DeGeoEM score in a case is 24 ( 4 dimensions times 6 levels). Not all levels on each dimeson must necessarily be completed, and the score does not need to be the maximum. In this case, the sum of the score of all dimensions is divided by 24 (maximum score) to indicate the distance from the perfect score (fig. 5). 

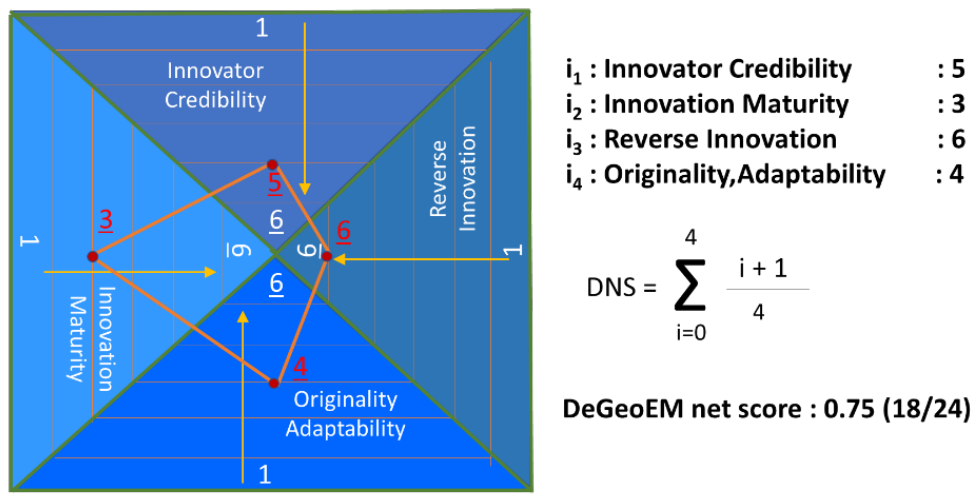

DeGeoEM net score : $0.75(18 / 24)$

Fig. 5. DeGeoEM Net Score calculation.

However and in order to be precise, the completion value of each level and each dimension is proposed to be calculated with level and dimensions multipliers set up by the investors per case giving the Weighted score.

The Weighted score is more precise as each level receives by the investor a multiplier according to the impact, complexity or criticality this level has for the specific investor. Not all levels have the same weight as some might be more impactful or difficult to be achieved than others. In a similar way, a second multiplier can be applied to the weight of the dimension itself. This indicates the importance of the dimensions based on the strategy of the investor (equation 1)

$$
\text { WNS }=\frac{\left[\sum_{\mathrm{i}=0}^{4}\left[\left(\text { Dim }_{\mathrm{i}}+1\right) * \text { Dim_Mult }_{\mathrm{i}}\right]+\left[\sum_{\mathrm{j}=0}^{6}\left(\text { Level }_{\mathrm{j}}+1\right) * \text { Level_Mult }_{\mathrm{j}}\right]\right.}{4}
$$

The Net and Weighted DeGeoEM scores can be used as a reference and benchmark for other investors in the future forming the DeGeoEM database of intentional startups or project evaluations. Investors seeking a specific type of innovation in India, for example, can search the DeGeoEM score database for similar cases in order to study the score position, level and distance from the reality after the investment has been made.

\section{Conclusions}

The Democratic Geo-Entrepreneurship Model approaches the democratization of innovation from an economic and social perspective. The economic perspective is related to the opportunities offered to any person who can think and innovate around the world without the need to be within the innovation branded cities and hubs. These opportunities can positively impact the lives of the innovators but also the profits of the investors. The model balances innovation opportunities around the world through the people. On the other hand, this social dimension extends beyond the impact on the lives of the people, to the fairness, equality and diversity the model supports. 
The model indirectly supports the social structures of the countries and their development route, buy tackling the devastating brain drain problem from which most of the emerging countries suffer. Providing investment opportunities to innovators to develop their innovations and business while staying, working and operating in their countries, contributes scientifically to the development of the country, the jobs creation in the country and the well-being of the people who prefer to stay, work and grow in their country. The developed countries can still enjoy financial benefits from reverse innovation and secure their investments while reducing the brain gain for them and the brain drain for the emerging markets. Metron Ariston is an Aristotelian principle for success that cannot be achieved in the absence of fairness or the presence of greed.

\section{References}

1. Hall D. : Entrecode: Unlocking the Entrepreneurial DNA. Management Books 2000 (2013)

2. Rugman A.M.: The Theory and Regulation of Emerging Market Multinational Enterprises. In: Sauvant K.P., McAllister G., Maschek W.A. (eds) Foreign Direct Investments from Emerging Markets. Palgrave Macmillan, New York. (2010)

3. CBInsignts: The 2014 U.S. Venture Capital Year in Review. Financing \& Exit Analysis (2015)

4. Corsi, S., Di Minin A: Disruptive Innovation ... in Reverse: Adding a Geographical Dimension to Disruptive Innovation Theory. Creativity and Innovation Management, Vol. 23, Issue 1. pp. 76--90. (2014)

5. Markopoulos E., Markopoulos P., Luimula M., Almufti Y., Romano C. : Digital Cultural Strategies Within the Context of Digital Humanities Economics. In: Ahram T. (eds) Advances in Human Factors in Wearable Technologies and Game Design. AHFE 2019. Advances in Intelligent Systems and Computing, vol 973. Springer, Cham. (2020)

6. European Commission : https://ec.europa.eu/commission/presscorner/detail/en/IP_18_3901

7. Cultnat : https://www.cultnat.org/

8. The Software Engineering Competence Center (SECC): https://www.secc.org.eg/

9. TIEC : https://www.tiec.gov.eg/English/Pages/default.aspx

10.Trading Economics: https://tradingeconomics.com/egypt/gdp-growth

11.World Intellectual Property Organization. https://www.wipo.int/pressroom/en/articles/2019/article_0008.html

12.The McKinsey Global Institute: https://www.mckinsey.com/featured-insights/innovationand-growth/outperformers-high-growth-emerging-economies-and-the-companies-that-propel-them

13.Morgan Stanley Capital International: https://www.msci.com/market-classification

14.Markopoulos E., Vanharanta H. : Democratic Culture Paradigm for Organizational Management and Leadership Strategies - The Company Democracy Model. In: Charytonowicz J. (ed) Advances in Human Factors and Sustainable Infrastructure. 5th International Conference on Applied Human Factors and Ergonomics. vol 20. pp 190-201 (2014)

15.Markopoulos E., Gann E.L., Vanharanta H.: Democratizing New Product Development Through an Industry-Society Entrepreneurial Partnership. In: Ahram T., Karwowski W., Pickl S., Taiar R. (eds) Human Systems Engineering and Design II. IHSED 2019. Advances in Intelligent Systems and Computing, chapter 127, vol 1026. Springer. (2020)

16.Markopoulos E., Aggarwal V., Vanharanta H.: Democratization of Intrapreneurship and Corporate Entrepreneurship Within the McKinsey's Three Horizons Innovation Space. In: Ahram T., Karwowski W., Pickl S., Taiar R. (eds) Human Systems Engineering and Design II. IHSED 2019. Advances in Intelligent Systems and Computing, chapter 151, vol 1026. Springer. (2020) 
17.Markopoulos E., Vanharanta H.: Public Sector Transformation via Democratic Governmental Entrepreneurship and Intrapreneurship. In: Ahram T., Karwowski W., Pickl S., Taiar R. (eds) Human Systems Engineering and Design II. IHSED 2019. Advances in Intelligent Systems and Computing, Chapter 132. vol 1026. Springer. (2020)

18.Markopoulos E., Kirane I.S., Piper C., Vanharanta H.: Green Ocean Strategy: Democratizing Business Knowledge for Sustainable Growth. In: Ahram T., Karwowski W., Pickl S., Taiar R. (eds) Human Systems Engineering and Design II. IHSED 2019. Advances in Intelligent Systems and Computing, chapter 20, vol 1026. Springer. (2020)

19.Markopoulos E., Umar O., Vanharanta H.: Agile Start-up Business Planning and Lean Implementation Management on Democratic Innovation and Creativity. In: Ahram T., Karwowski W., Pickl S., Taiar R. (eds) Human Systems Engineering and Design II. IHSED 2019. Advances in Intelligent Systems and Computing, chapter 134, vol 1026. Springer. (2020)

20.Markopoulos E., Vanharanta H.: Project teaming in a democratic company context. Theoretical Issues in Ergonomics Science, 19:6, pp.673-691. (2018)

21.Entrepreneur Europe: https://www.entrepreneur.com/article/288769 